\title{
The flipped classroom: for active, effective and increased learning - especially for low achievers
}

Open Access

\author{
Jalal Nouri
}

\author{
Correspondence: jalal@dsv.su.se \\ Department of Computer and \\ Systems sciences, Stockholm \\ University, Stockholm, Sweden
}

\begin{abstract}
Higher education has been pressured to shift towards more flexible, effective, active, and student-centered teaching strategies that mitigate the limitations of traditional transmittal models of education. Lately, the flipped classroom model has been suggested to support this transition. However, research on the use of flipped classroom in higher education is in its infancy and little is known about student's perceptions of learning through flipped classroom. This study examined students' perceptions of flipped classroom education in a last year university course in research methods. A questionnaire was administered measuring students' $(n=240)$ perceptions of flipped classroom in general, video as a learning tool, and Moodle (Learning Management System) as a supporting tool within the frame of a flipped classroom model. The results revealed that a large majority of the students had a positive attitude towards flipped classroom, the use of video and Moodle, and that a positive attitude towards flipped classroom was strongly correlated to perceptions of increased motivation, engagement, increased learning, and effective learning. Low achievers significantly reported more positively as compared to high achievers with regards to attitudes towards the use of video as a learning tool, perceived increased learning, and perceived more effective learning.
\end{abstract}

Keywords: Teaching/learning strategies, Distributed learning environments, Improving classroom teaching, Interactive learning environments, Post- secondary education

\section{Introduction}

Teaching at the university level has been performed in a relatively similar manner during a long historical time and across cultures. As a central pillar, we find the traditional lecture with the professor, or the "sage on the stage" as put by King (1993), transmitting knowledge to receiving students. Nevertheless, over the past 30 years, university education and traditional lectures in particular have been strongly criticized. The main criticism has cast light on the following: students are passive in traditional lectures due to the lack of mechanisms that ensure intellectual engagement with the material, student's attention wanes quickly, the pace of the lectures is not adapted to all learners needs and traditional lectures are not suited for teaching higher order skills such such as application and analysis (Cashin, 1985; Bonwell, 1996; Huxham, 2005; Young, Robinson, \& Alberts, 2009). Consequently, various researchers and educators have advocated forms of lecturing based on an active learning philosophy, some involving novel technology mediated

(c) 2016 The Author(s). Open Access This article is distributed under the terms of the Creative Commons Attribution 4.0 International License (http://creativecommons.org/licenses/by/4.0/), which permits unrestricted use, distribution, and reproduction in any medium, provided you give appropriate credit to the original author(s) and the source, provide a link to the Creative Commons license, and indicate if changes were made. 
interactions (Beekes, 2006; Rosie, 2000), others without an explicit focus on technology such as the enhanced lecture of Bonwell (1996). However, despite the comprehensive critique, the traditional lecture continues to prevail as the predominant didactic strategy in higher education (Roehl, Reddy, \& Shannon, 2013).

It is against such a background, and to high extent because of advancements in educational technology, increasing pressures on higher education have been witnessed that have spawned a push to flexible blended student-centered learning strategies that mitigate the limitations of the transmittal model of education (Betihavas, Bridgman, Kornhaber, \& Cross, 2015). Accompanied with the shift to provide student-centered learning we have seen a surge of researchers and educators advocating flipped classroom curricula in higher education. The advocacy of the flipped classroom model is justifiable. Judging by its underlying theory and the conducted empirical studies, the flipped classroom model appears to address several challenges with traditional ways of lecturing and pave way for active learning strategies and for using classroom time for engaging in higher levels of Bloom's taxonomy (Krathwohl, 2002) such as application, analysis, and synthesis.

The flipped classroom model is based on the idea that traditional teaching is inverted in the sense that what is normally done in class is flipped or switched with that which is normally done by the students out of class. Thus, instead of students listening to a lecture in class and then going home to work on a set of assigned problems, they read course literature and assimilate lecture material through video at home and engage in teacher-guided problem-solving, analysis and discussions in class. Proponents of flipped classroom list numerous advantages of inverting teaching and learning in higher education according to the flipped classroom model: it allows students to learn in their own pace, it encourages students to actively engage with lecture material, it frees up actual class time for more effective, creative and active learning activities, teachers receive expanded opportunities to interact with and to assess students' learning, and students take control and responsibility for their learning (Gilboy, Heinerichs, \& Pazzaglia, 2015; Betihavas et al., 2015).

Despite that flipped classroom is a rather new phenomenon in higher education, some empirical research has been conducted. For instance, McLaughlin et al. (2013) and McLaughlin et al. (2014) analysis of pharmacy students' experiences of flipped classroom courses revealed that students prefer learning content prior to class and using class time for applied learning, and that students who learned through a flipped classroom approach considered themselves more engaged than students attending traditional courses. Similar findings were obtained by Davies, Dean, and Ball (2013) who compared three different instructional strategies in an information systems spreadsheet course, and showed that students attending the flipped classroom course also were more satisfied with the learning environment compared to the other treatment groups. Several studies report that students enjoy being able to learn in their own pace and that they prefer flipped classroom over traditional approaches (Butt, 2014; Davies et al., 2013; Larson \& Yamamoto, 2013; McLaughlin et al., 2014; Roach, 2014; Gilboy et al., 2015). In term of examinations of learning outcomes, Love, Hodge, Grandgenett, and Swift (2014) demonstrated higher exam grades for students using a flipped classroom approach as compared to students learning through traditional methods. Hung (2015) showed similar results for English language learners. Another study by Findlay- 
Thompson and Mombourquette (2014) comparing traditional teaching methods and the flipped classroom approach within the same business course showed no significant differences in academic outcomes.

However, empirical research on the flipped classroom model in higher education, and more detailed investigations of students' perceptions of its use, is in its infancy and the need for further research is underlined by many (Bishop \& Verleger, 2013; Uzunboylu \& Karagozlu, 2015; Betihavas et al., 2015; Gilboy et al., 2015).

\section{Research purpose}

The purpose of this study was to examine how students perceive flipped classroom education in a university research methods course. Three particular aspects were considered, namely, (a) the student's general experiences and attitudes of learning through flipped classroom, (b) the student's experiences of using video lectures as a medium for learning, and (c) the student's experiences of using a Learning Management System (LMS) in the frame of the flipped classroom model. Further, this study has also considered differences in experiences and attitudes of low and high achieving students.

\section{Method}

This study is based on a quantitative analysis of a closed questionnaire addressing undergraduate students' perceptions and experience of learning through flipped classroom in a course preparing students for the bachelor thesis with respect to scientific methodology and communication. The course was implemented during autumn 2015.

\section{Participants}

The participants were undergraduate students $(n=240)$ at Stockholm University in Sweden taking the last year course Research methods and communication during autumn semester 2015. All of the students were enrolled in 8 different bachelor level programs at the department of Computer and Systems Sciences. The students, 76 females and 164 males, ranged in age from 20 to 43 years, with a mean age of 25.12 years (SD $=4.09$ ). Out of the 240 students only 23 had a previous experience of flipped classroom. The number of students passing the course was 218. Table 1 presents an overview of

Table 1 Student demographics and other background questions

\begin{tabular}{|c|c|c|c|c|}
\hline Background questions & $\mathrm{n}$ & Percent & M & SD \\
\hline Age & 240 & & 25.12 & 4.01 \\
\hline \multicolumn{5}{|l|}{ Gender } \\
\hline Women & 76 & 31.7 & & \\
\hline Men & 164 & 68.3 & & \\
\hline \multicolumn{5}{|l|}{ Low and high achievers } \\
\hline Low & 202 & 84.2 & & \\
\hline High & 38 & 15.8 & & \\
\hline Average grade during studies & 240 & & 2.91 & 0.67 \\
\hline Average grade on the course & 240 & & 3.29 & 0.88 \\
\hline I am used to learn using video & 240 & & 3.67 & 1.01 \\
\hline
\end{tabular}


student demographics and background questions. Low and high achievers among the students were determined by the student's average grade during their studies. Here high achievers were defined as having average grades A to B while low achievers were defined as having average grades $\mathrm{C}$ to $\mathrm{F}$.

\section{Materials and procedure}

\section{Course structure}

The course focused on in this study prepares students for the bachelor thesis with respect to scientific methodology and communication. The learning objectives are on the one hand to facilitate students understanding of the fundamentals of research strategies, data-collection methods, and analysis methods, and on the other hand to familiarize students with application of qualitative and quantitative methods of analysis. Put differently, the course aimed at equipping students with conceptual knowledge (an understanding of scientific methods), and procedural knowledge (application of analysis methods and scientific writing). See Fig. 1 for the underlying pedagogical structure.

The course was divided into three parts with three different examination tasks. The first part concerned gaining a theoretical understanding of the fundamentals of research strategies, data-collection methods, and analysis methods. The pedagogical structure for this part comprised of independent reading of course literature. Students reading of the course literature was supported by three longer video lectures (in average $60 \mathrm{~min}$ each), one traditional campus lecture (teacher presenting and summarizing the fundamentals of research strategies), and one interactive flipped classroom lecture in which the teacher presented examples of exam questions that students answered in real-time by using a digital response system (Socrative) via their own smart phones, tablets and computers. The response system provided an overview of the responses that allowed students to assess their knowledge and the teacher to provide formative feedback and elaborated explanations when needed. In addition, digital supervision was offered through a learning management system (Moodle). The examination for this part comprised of a multiple-choice digital exam in the learning management system.

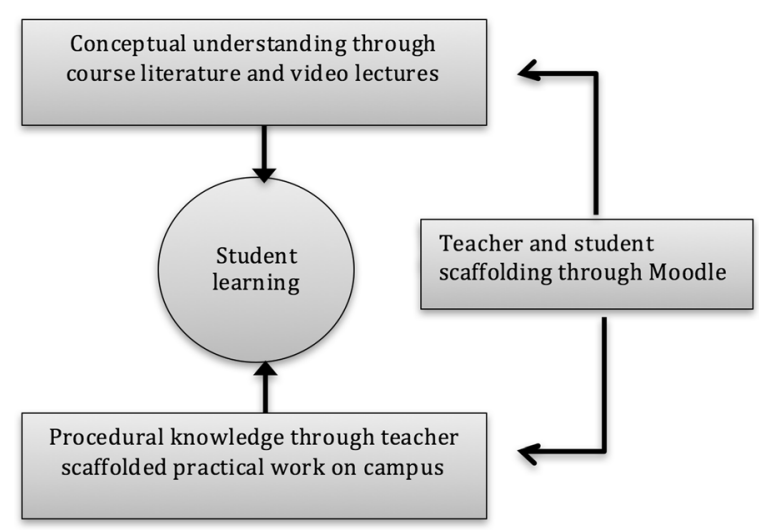

Fig. 1 Pedagogical structure for students conceptual and procedural learning 
The second part was a practical qualitative analysis project that students conducted in groups of two. The task of this project was to use a qualitative analysis method to analyze qualitative interview data and communicate the results in a report following scientific standards of qualitative data presentation. During this project the students were supported by five digital lectures (in average $35 \mathrm{~min}$ each), three flipped lectures on campus, and digital supervision through the learning management system. In the three flipped lectures on campus students worked with their projects and were scaffolded by several teachers that answered questions and provided feedback. When the teachers identified common misunderstandings or needs among the students, they provided elaborated explanations to the whole class. The examination of the second part comprised of a written group report.

The third part of the course was similar to the second part, comprising of a project with a focus on using quantitative methods to analyze a questionnaire and communicate the results according to scientific standards of quantitative result presentation. During this project the students were supported by seven video lectures (in average $30 \mathrm{~min}$ each), three flipped lectures in class with teachers scaffolding practical work, and digital supervision in the learning management system. The videos covered the theoretical fundamentals of descriptive and inferential statistics as well as how different statistical tests can be performed and interpreted in SPSS. The examination of the third part comprised of a written group report.

All video lectures made available to the students during the course were produced by teachers and researchers in a professional video studio at Stockholm University. The video lectures were specifically tailored for the course.

\section{Survey measures and procedure}

A questionnaire was developed consisting of 4 sections with 58 items to measure students' perceptions of flipped classroom in general, video as a learning tool, and Moodle as a supporting system.

- Section 1 (General information) consisted of 12 demographic and background items

- Section 2 (Flipped Classroom Scale) consisted of 21 items measuring students' experiences and attitudes of learning through flipped classroom

- Section 3 (Video Scale) consisted of 16 items measuring students' experiences of using video lectures as a medium for learning.

- Section 4 (LMS scale) consisted of 9 items measuring students' perceptions of the utility of Moodle in supporting their learning processes within the frame of flipped classroom pedagogy.

An exploratory factor analysis with principal component extraction was performed in an attempt to refine the instrument. After factor analysis, 8 items that did not load on any factors or highly cross-loaded on multiple factors were removed. Accordingly, the instrument used for the final analysis consisted of 17 items for the Flipped Classroom Scale, 13 items for the Video Scale, and 5 items for the LMS Scale. Overall, Cronbach's alphas were .78 for the Flipped Classroom Scale, .82 for the Video Scale, and .84 for the LMS Scale. Students were asked to complete the questionnaire at the end of the course. The questionnaire was developed and administered through a web tool. 


\section{Results}

\section{Students' general perceptions of flipped classroom}

The flipped classroom model proved to be appreciated by many students. Among the 240 respondents, 180 students expressed a positive attitude to flipped classroom after the course $(75 \%)$. The students most appreciated the use of video $(\mathrm{M}=4.15, \mathrm{SD}=1.10)$, flexibility and mobility given by the flipped classroom model $(M=3.95, S D=1.10)$, that learning can be done at own pace $(M=3.75$, $\mathrm{SD}=0.91)$, that learning processes are better supported $(M=3.54, \mathrm{SD}=1.13)$, and that non-traditional campus activities are meaningful $(M=3.40, S D=1.13)$.

In terms of other characteristics of the learning process, to some extent the students appeared to agree that it is easier and more effective to learn with the flipped classroom approach $(M=3.17, S D=1.03)$ and that they feel more motivated as learners $(M=2.95$, $\mathrm{SD}=1.13)$. Furthermore, many students perceived that they had to take more responsibility for their learning $(M=3.91, S D=0.96)$ in a flipped classroom course.

Noteworthy, some students also felt themselves alone during their learning $(M=3.01$, $\mathrm{SD}=1.29)$. Table 2 shows the students' experiences of flipped classroom after the course was completed.

The results of an analysis of the correlations between the measured variables, with a particular focus on attitudes towards flipped classroom and its effect on learning and motivation is presented in Table 3. Students with positive attitudes towards flipped classroom more likely had positive attitudes towards video $(p<0.01)$, experienced

Table 2 Students' experiences of flipped classroom after the course

\begin{tabular}{|c|c|c|c|c|}
\hline Experiences of flipped classroom & $n$ & Percent & M & SD \\
\hline \multicolumn{5}{|c|}{ I have a positive attitude towards flipped classroom after the course } \\
\hline Yes & 180 & 75.00 & & \\
\hline No & 60 & 25.00 & & \\
\hline \multicolumn{5}{|l|}{ I have a prior experience of flipped classroom } \\
\hline Yes & 23 & 09.60 & & \\
\hline No & 217 & 90.40 & & \\
\hline I appreciate learning with video & 240 & & 4.15 & 1.10 \\
\hline I am more flexible and mobile as learner & 240 & & 3.95 & 1.10 \\
\hline I have to take more responsibility for learning & 240 & & 3.91 & 0.96 \\
\hline I can study in my own pace & 240 & & 3.75 & 0.91 \\
\hline My learning processes are more supported & 240 & & 3.54 & 1.13 \\
\hline The non-traditional classroom activities were meaningful & 240 & & 3.40 & 1.13 \\
\hline It is easier and more effective to learn & 240 & & 3.17 & 1.03 \\
\hline I do more studying/learning on my own spare time & 240 & & 3.03 & 1.25 \\
\hline I feel more alone & 240 & & 3.01 & 1.29 \\
\hline I am more motivated as learner & 240 & & 2.95 & 1.13 \\
\hline I am more active as a learner & 240 & & 2.81 & 1.16 \\
\hline I learn more & 240 & & 2.74 & 1.07 \\
\hline I feel an increased workload that is stressful & 240 & & 2.61 & 1.20 \\
\hline I experience stronger peer-collaboration & 240 & & 2.45 & 1.01 \\
\hline It feels like a distance course & 240 & & 2.43 & 1.30 \\
\hline
\end{tabular}

Likert scale items measured on a 5 -point scale ranging from $1=$ strongly disagree to $5=$ strongly agree 
Table 3 Correlations between variables

\begin{tabular}{llllllll}
\hline Variable & 1 & 2 & 3 & 4 & 5 & 6 & 7 \\
\hline 1. Attitude towards FC & 1,00 & & & & & & \\
2. Attitude towards video &, $74^{* *}$ & 1,00 & & & & \\
3. Increased motivation &, $81^{* *}$ &, $80^{* *}$ & 1,00 & & & \\
4. More effective learning &, $85^{* *}$ &, $85^{* *}$ &, $74^{* *}$ & 1,00 & & \\
5. Increased learning &, $82^{* *}$ &, $87^{* *}$ &, $74^{* *}$ &, $89^{* *}$ & 1,00 & \\
6. More active learner &, $80^{* *}$ &, $58^{* *}$ &, $68^{* *}$ &, $70^{* *}$ &, $70^{* *}$ & 1,00 \\
7. More responsibility for learning &, $67^{* *}$ &, $47^{* *}$ &, $49^{* *}$ &, $52^{* *}$ &, $49^{* *}$ &, $44^{* *}$ & 1,00 \\
\hline
\end{tabular}

* $p$ significant at 0.05

** $p$ significant at 0.01

increased motivation $(p<0.01)$, more effective learning $(p<0.01)$, and increased learning $(p<0.01)$. They also tended to agree that flipped classroom made them more active as learners $(p<0.01)$ and take more responsibility for their learning $(p<0.01)$.

\section{The use of video as a learning tool}

Using flipped classroom and in particular video as a tool for assimilating knowledge otherwise presented in traditional lectures proved to correlate strongly with perceived increased motivation, increased learning and effective learning. When analyzing the student's experiences of using video as a learning tool in more detail a number of reasons for appreciating video stand out (see Table 4 for an overview). The students strongly agreed that it was useful for their learning to be able to pause $(M=4.52, S D=0.85)$, rewind $(M=$ $4.48, \mathrm{SD}=0.87)$ and fast-forward video $(\mathrm{M}=4.04, \mathrm{SD}=1.36)$. They also agreed that the combination of video and non-traditional lectures was useful $(\mathrm{M}=3.73, \mathrm{SD}=1.16)$ as well as being able to watch lectures in a mobile way $(\mathrm{MD}=3.98, \mathrm{SD}=1.28)$.

The use of Moodle within the frame of flipped classroom

A learning management system (Moodle) was used during the course to support students' learning processes within the frame of a flipped classroom model. As presented

Table 4 Students' experiences of using video for learning

\begin{tabular}{llll}
\hline Experiences of using video for learning & $\mathrm{n}$ & $\mathrm{M}$ & $\mathrm{SD}$ \\
\hline Useful to pause video & 231 & 4.52 & 0.85 \\
Useful to rewind video & 228 & 4.48 & 0.87 \\
Useful to fast-forward video & 210 & 4.04 & 1.36 \\
Useful to watch lectures in a mobile way & 240 & 3.98 & 1.28 \\
The combination of video and non-traditional lectures was useful & 240 & 3.73 & 1.16 \\
Video made learning more effective & 240 & 3.54 & 1.19 \\
Video quality was satisfactory & 240 & 3.48 & 1.23 \\
Video made me learn more & 240 & 3.38 & 1.22 \\
Video motivated me to learn & 240 & 3.26 & 1.15 \\
Video can replace traditional lectures completely & 240 & 2.59 & 1.33 \\
I rather have traditional lectures than video & 240 & 2.48 & 1.34 \\
Learning through video resulted in more peer discussions & 240 & 1.43 & 0.50 \\
\hline
\end{tabular}

Likert scale items measured on a 5 -point scale ranging from $1=$ strongly disagree to $5=$ strongly agree 
in Table 5, the students appreciated this support $(\mathrm{M}=4.22, \mathrm{SD}=0.86)$. In particular, they found it useful to be able to see other students' questions posed in Moodle and the teachers answers to those questions $(\mathrm{M}=4.39, \mathrm{SD}=0.94)$, and for general communication with teachers $(M=4.07, S D=1.05)$. Interestingly, the LMS itself contributed to some student's motivation to learn $(\mathrm{M}=3.40, \mathrm{SD}=1.26)$.

\section{Comparing low and high achievers}

When comparing low and high achievers among the students in terms of attitudes towards flipped classroom, video and the effect on learning and motivation some interesting findings were obtained. The results of conducted independent sample t-tests showed no significant differences in positive attitudes to flipped classroom of low achievers $(M=3.37, S D=0.74)$ and high achievers $(M=3.20, S D=0.87), t(238)=2.13$, $p>0.05$. Significant differences were however revealed with regards to attitudes towards the use of video of low achievers $(M=3.10, S D=0.72)$ and high achievers $(M=2.67$, $\mathrm{SD}=1.02), \mathrm{t}(238)=3.17, p<0.05$.

Interestingly, the perception of increased learning also significantly differed between low achievers $(M=3.13, S D=0.93)$ and high achievers $(M=2.71, S D=1.23)$, $\mathrm{t}(238)=2.40, p<0.05$. The tests likewise showed significant differences in perceived more effective learning of low achievers $(\mathrm{M}=3.25, \mathrm{SD}=0.95)$ and high achievers $(\mathrm{M}=2.80, \mathrm{SD}=1.32), \mathrm{t}(238)=2.46, p<0.05$. However, no significant differences could be identified between low achievers and high achievers in the other variables measured (see Table 6).

\section{Conclusions}

The calls for reforming traditional higher education teaching, and for transforming the sage on the stage into the guide on the side in order to pave way for student-centered active learning strategies have probably never been as loud as now. In this context, flipped classroom has been proposed to answer these calls. Several studies have demonstrated that flipped classroom as a teaching method may promote student engagement and a more active approach to learning in higher education. The findings from this study confirm the results of these studies and highlights additional advantages associated with the flipped classroom model.

The students in the study's sample were found to generally appreciate the flipped classroom. The most commonly valued reasons for this was that the students appreciated learning through using video material, the opportunity to study in their own pace, flexibility and mobility brought about by accessible video lectures, and that learning is easier and more effective within the frame of the flipped classroom.

Table 5 Students' experiences of using the learning management system (Moodle)

\begin{tabular}{llll}
\hline Experiences of using Moodle & $\mathrm{n}$ & $\mathrm{M}$ & $\mathrm{SD}$ \\
\hline It was useful to see other students questions and teacher answers in Moodle & 240 & 4.39 & 0.94 \\
Moodle supported my learning & 240 & 4.22 & 0.86 \\
It was useful to communicate with teachers through Moodle & 240 & 4.07 & 1.05 \\
Moodle motivated me to learn & 240 & 3.40 & 1.26 \\
\hline
\end{tabular}

Likert scale items measured on a 5 -point scale ranging from $1=$ strongly disagree to $5=$ strongly agree 
Table 6 Comparing low- and high achievers experience of flipped classroom

\begin{tabular}{|c|c|c|c|c|c|c|}
\hline Experiences of flipped classroom & Achiever & M & SD & $\mathrm{F}$ & $\mathrm{t}$ & $p$ \\
\hline \multirow[t]{2}{*}{ Positive attitude towards FC } & Low & 3.10 & 0.72 & 2.13 & 1.25 & 0.21 \\
\hline & High & 2.67 & 1.02 & & & \\
\hline \multirow[t]{2}{*}{ Increased motivation } & Low & 3.16 & 0.94 & 4.56 & 1.95 & 0.52 \\
\hline & High & 2.81 & 1.22 & & & \\
\hline \multirow[t]{2}{*}{ Increased learning } & Low & 3.13 & 0.93 & 10.10 & 2.40 & 0.01 \\
\hline & High & 2.71 & 1.23 & & & \\
\hline \multirow[t]{2}{*}{ More effective learning } & Low & 3.25 & 0.95 & 12.09 & 2.46 & 0.01 \\
\hline & High & 2.80 & 1.32 & & & \\
\hline \multirow[t]{2}{*}{ Attitude towards video } & Low & 3.10 & 0.72 & 11.22 & 3.17 & 0.02 \\
\hline & High & 2.67 & 1.02 & & & \\
\hline \multirow[t]{2}{*}{ More active learner } & Low & 2.86 & 1.14 & 2.08 & 1.47 & 0.14 \\
\hline & High & 2.55 & 1.27 & & & \\
\hline \multirow[t]{2}{*}{ More responsibility for learning } & Low & 3.55 & 1.00 & 0.08 & 0.45 & 0.65 \\
\hline & High & 3.47 & 1.06 & & & \\
\hline
\end{tabular}

p significant at 0.05

A correlation analysis further demonstrated significant strong correlations between students' appreciation of the flipped classroom experience on the one hand, and attitudes towards video as a learning tool, increased motivation, increased learning, more effective learning and more active learning on the other hand.

Interestingly, independent sample t-tests showed significant differences between low and high achievers in that the low achievers tended to have more positive attitudes towards the use of video as a learning tool. Low achievers also to higher extent perceived increased and more effective learning through flipped classroom. A more detailed analysis of the students' experiences of using video showed that the most valued aspects of video use was being able to pause and rewind the video lectures. Against this fact, it is not unreasonable to conclude that low achievers, who might find traditional lectures challenging and fast-paced (Young et al., 2009), experienced an empowerment using the flipped classroom model in terms of gaining more opportunities to reflect and learn in their own pace.

For all students in general, the results indicate that the reasons for students' perceptions of increased and more effective learning are associated with: 1) the affordances of video lectures (the ability to reflect and learn in own pace); 2) more meaningful practice-oriented and teacher supervised classroom activities; and 3) more supported learning processes due to teacher and peer scaffolding in class and out of class through the use of Moodle.

Thus, as final remarks, considering the ineffectiveness of traditional lectures in retaining students' attention and promoting active learning (Windschitl, 1999; Young et al., 2009) in higher education, the results of this study indicate that the flipped classroom model seem to offer promising ways to engage students in more effective, supportive, motivating and active learning, especially for low achievers and students that may struggle with traditional lectures. However, the results should be viewed in light of the limitations of this study. One such limitation is the non existence of a control group which limits the external validity of the results. Another limitation is connected 
to the fact that the majority of the student's surveyed have not experienced flipped classroom before, thus the results may partly reflect the influence of a new approach of learning and teaching and not necessary the influence of the flipped classroom approach. It also should be noted that all results related to improved learning and effectiveness of learning is based on students self-declared perceptions and not on independent measures. Future studies on the effects of flipped classroom should address these limitations and in particular explore the extent to which the actual performance of students is or is not affected by the flipped classroom approach moving beyond just student perceptions.

Competing interests

The author declares that he has no competing interests.

Received: 27 February 2016 Accepted: 14 July 2016

Published online: 24 August 2016

References

Beekes, W. (2006). The "millionaire" method for encouraging participation. Active Learning in Higher Education, $7(1), 25-36$

Betihavas, V., Bridgman, H., Kornhaber, R., \& Cross, M. (2015). The evidence for 'flipping out': A systematic review of the flipped classroom in nursing education. Nurse Education Today, 6, 15-21.

Bishop, J. L., \& Verleger, M. A. (2013). The flipped classroom: a survey of the research. In ASEE National Conference Proceedings, Atlanta, GA.

Bonwell, C. C. (1996). Enhancing the lecture: revitalizing a traditional format. New Directions for Teaching and Learning, 1996(67), 31-44.

Butt, A. (2014). Student views on the use of a flipped classroom approach: evidence from Australia. Business Education \& Accreditation, 6(1), 33-43.

Cashin, W. E. (1985). Improving lectures. Idea paper no. 14. Manhattan: Kansas State University, Center for Faculty Evaluation and Development.

Davies, R. S., Dean, D. L., \& Ball, N. (2013). Flipping the classroom and instructional technology integration in a collegelevel information systems spreadsheet course. Educational Technology Research and Development, 61(4), 563-580.

Findlay-Thompson, S., \& Mombourquette, P. (2014). Evaluation of a flipped classroom in an undergraduate business course. Business Education \& Accreditation, 6(1), 63-71.

Gilboy, M. B., Heinerichs, S., \& Pazzaglia, G. (2015). Enhancing student engagement using the flipped classroom. Journal of nutrition education and behavior, 47(1), 109-114.

Hung, H. (2015). Flipping the classroom for English language learners to foster active learning. Computer Assisted Language Learning, 28(1), 81-96.

Huxham, M. (2005). Learning in lectures Do 'interactive windows' help? Active learning in higher education, 6(1), 17-31.

King, A. (1993). From sage on the stage to guide on the side. College teaching, 41(1), 30-35.

Krathwohl, D. R. (2002). A revision of Bloom's taxonomy: an overview. Theory into practice, 41(4), 212-218.

Larson, S., \& Yamamoto, J. (2013). Flipping the college spreadsheet skills classroom: initial empirical results. Journal of Emerging Trends in Computing and Information Sciences, 4(10), 751-758.

Love, B., Hodge, A., Grandgenett, N., \& Swift, A. (2014). Student learning and perceptions in a flipped linear algebra course. International Journal of Mathematical Education in Science and Technology, 45(3), 317-324.

McLaughlin, J. E., Griffin, L. M., Esserman, D. A., Davidson, C. A., Glatt, D. M., Roth, M. T., ...Mumper, R. J. (2013). Pharmacy student engagement, performance, and perception in a flipped satellite classroom. American Journal of Pharmaceutical Education, 77(9), 196.

McLaughlin, J. E., Roth, M. T., Glatt, D. M., Gharkholonarehe, N., Davidson, C. A., Griffin, L. M., ...Mumper, R. J. (2014). The flipped classroom: a course redesign to foster learning and engagement in a health professions school. Academic Medicine, 89(2), 236-243.

Roach, T. (2014). Student perceptions toward flipped learning: new methods to increase interaction and active learning in economics. International Review of Economics Education, 17, 74-84.

Roehl, A., Reddy, S. L., \& Shannon, G. J. (2013). The flipped classroom: an opportunity to engage millennial students through active learning strategies. Journal of Family \& Consumer Sciences, 105(2), 44-49.

Rosie, A. (2000). "Deep learning": a dialectical approach drawing on tutor-led web resources. Active Learning in Higher Education, 1(1), 45-59.

Uzunboylu, H., \& Karagozlu, D. (2015). Flipped classroom: a review of recent literature. World Journal on Educational Technology, 7(2), 142-147.

Windschitl, M. (1999). Using small-group discussions in science lectures. College Teaching, 47(1), 23-7.

Young, M. S., Robinson, S., \& Alberts, P. (2009). Students pay attention! Combating the vigilance decrement to improve learning during lectures. Active Learning in Higher Education, 10(1), 41-55. 